\title{
Huge mucinous cystadenoma of ovary with massive third degree uterovaginal prolapse in postmenopausal woman: rare case report and review of literature
}

\author{
Rajshree Dayanand Katke*
}

\begin{abstract}
Department of Obstetrics \& Gynaecology, Cama \& Albless Hospital, Grant Government Medical College \& Sir J. J. Group of Hospitals, Mumbai, Maharashtra, India
\end{abstract}

Received: 08 November 2014

Accepted: 10 December 2014

\section{*Correspondence:}

Dr. Rajshree Dayanand Katke,

E-mail: drrajshrikatke@gmail.com, drrajshreekatke.blogspot.in

Copyright: $(\mathbb{C}$ the author(s), publisher and licensee Medip Academy. This is an open-access article distributed under the terms of the Creative Commons Attribution Non-Commercial License, which permits unrestricted non-commercial use, distribution, and reproduction in any medium, provided the original work is properly cited.

\begin{abstract}
Mucinous cystadenomas make up $15-20 \%$ of all ovarian tumors. They often become very large and can extend up into the abdomen. These tumors are usually evaluated using ultrasound, CT scan, or MRI. Findings on imaging studies are nonspecific. These ovarian tumors are usually multi-septated, cystic masses with thin walls. They also contain varying amounts of solid tissue which consists of proliferating stromal tissue, papillae, or malignant tumor cells. Benign mucinous cystadenomas compose $80 \%$ of mucinous ovarian tumors and $20-25 \%$ of benign ovarian tumors overall. The peak incidence occurs between 30-50 years of age. Benign tumors are bilateral in 5-10\% of cases. Here we would like to present a case of huge benign mucinous cystadenoma with procedentia in a 70 year old female where the patient could not access medical care, and presented with huge tumour which lead to pressure symptoms and responded remarkably to surgical excision. The patient could go back to her normal life following the procedure.
\end{abstract}

Keywords: Huge benign mucinous cystadenoma, Huge uterovaginal prolapse

\section{INTRODUCTION}

Benign ovarian mucinous tumors are rare at the extremities of age, before puberty and after menopause. They are common between the third and the fifth decades. Mucinous cystadenomas may reach huge size as a matter of fact; many of the largest human tumours belong to this group. Grossly these tumours appear as rounded, ovoid or irregularly lobulated growths with a smooth outer surface of whitish or bluish white hue. The wall in many areas is so thin as to be translucent. Although adhesions to surrounding organs may be present, they usually represent inflammatory adhesions and do not connote malignant extension. They are attached to the infundibulopelvic ligament by a relatively narrow pedicle that contains the markedly increased supply for the tumour. The content of the cyst is generally a clear viscid fluid, sometimes very thick at other times thin; a mixture of blood elements may give it a chocolate or brownish hue. This fluid is usually rather thin and flows freely at body temperature, but congeals and becomes gelatinous as it cools. The cut surface shows the cavity to be divided by septa into varying number of compartments or locules, these tumours have therefore often been spoken as a multilocular cyst. Microscopically, the distinctive feature of mucinous cysts is the characteristic single layer often undulating outline, of tall, pale staining secretory epithelium, with nuclei placed at the basal poles of the cells, goblet cells are often seen, on occasion, even paneth and argentaffin cells are noted Pseudomyxomaperitonii is often associated with mucinous cyst of ovary and mucocele of appendix and carcinoma of large bowel. ${ }^{3}$ Although a TAH with BSO with omentectomy with peritoneal biopsies remains the procedure of choice in such cases (where the family is 
complete), we may need to try alternative procedures (such as a supracervical hysterectomy) in the case of preexisting complications. ${ }^{4}$

\section{CASE REPORT}

A 75 years female postmenopausal multiparous women was referred from an Institute for massive third degree uterovaginal prolapse since 2 years and lump in abdomen since 4 months. The patient was apparently alright 2 years back when she complaint of something coming out of vagina which initially was till introitus and reducible. It gradually increased till whole uterus came out of introitus. It was still reducible. Patient also started complaint painless lump in abdomen since last 4 months. Patient was a known case of hypertension since 2 years and was taking tablet amlodipine $5 \mathrm{mg}$ OD. On examination, her general condition was fair. Her pulse was 76 beats per minute and blood pressure was 130/70 $\mathrm{mmHg}$. Her cardiorespiratory findings were unremarkable. On per abdomen examination, a mass corresponding to 36 weeks size of uterus, hard, irregular, immobile, non-tender was felt with ascites. On local examination, third degree uterovaginal prolapse with huge cystocele and rectocele. No demonstrable stress urinary incontinence. Cervix was congested circumferentially without any evidence of trophic ulcer. On per vaginal examination, uterus was atrophic, reteroverted and mass was felt through fornices. On Per Rectal examination rectal mucosa was free. Her routine blood and urine investigations were within normal limits. Her Pap smear was suggestive of no evidence of malignant cells. Her tumour marker levels were as follows: CA 125 was $50 \mathrm{U} / \mathrm{mL}$ (Normal value $<35$ $\mathrm{U} / \mathrm{mL}$ ), CEA (Carcino embryonic antigen) 25.1 (Normal Value $0-2.5 \mathrm{ng} / \mathrm{ml}$ ), Her CA 19.9 was $2.8 \mathrm{U} / \mathrm{ml}$ (normal value $0-35 \mathrm{U} / \mathrm{ml}$ ).

Ultrasound showed (Abdomen + Pelvis) was large cystic mass in lower abdomen. Uterus is not seen due to the mass. The cystic mass with multiple septae in lower abdomen is of size $21.1 \mathrm{~cm} \times 14.5 \mathrm{~cm} \times 11.6 \mathrm{~cm}$. Her computed tomography contrast (Abdomen +Pelvis) was suggestive of large cystic lesion in pelvis extending into abdomen till T2 vertebral body, $22 \mathrm{~cm} \times 21 \mathrm{~cm} \times 11 \mathrm{~cm}$ in size with multiple enhancing septae noted in the lesion without any calcification or fat seen. Uterus is of small size and ovaries are not identified. Mild ascites and mild omental nodularity present. Tiny cyst in segment IV of liver most likely simple cyst. Well defined lesion at GE junction benign neoplastic in etiology. Her 2D Echo was normal. Her sputum routine \& culture was negative for AFB. Her Orogastroduodenoscopy was suggestive of Reflux esophagitis. Exploratory laparotomy with excision of large ovarian tumour with frozen section followed by total abdominal hysterectomy with removal of other side Fallopian tubes as other side ovaries were not seen separately from tumour. In situ findings were a mass arising from ovaries $26 \mathrm{~cm} \times 25 \mathrm{~cm} \times 24 \mathrm{~cm}$ in size irregular surface, solid cystic with increased vascularity.
Bilateral ovaries were not visualized separately from the mass. Uterus was atrophic. Tumour mass was excised and sent for frozen section. Frozen section report was suggestive of mucinous cystic neoplasm. No invasive carcinoma detected in frozen section. Final histopathology report is suggestive of mucinous cystadenoma of ovary. No atypia or malignancy.

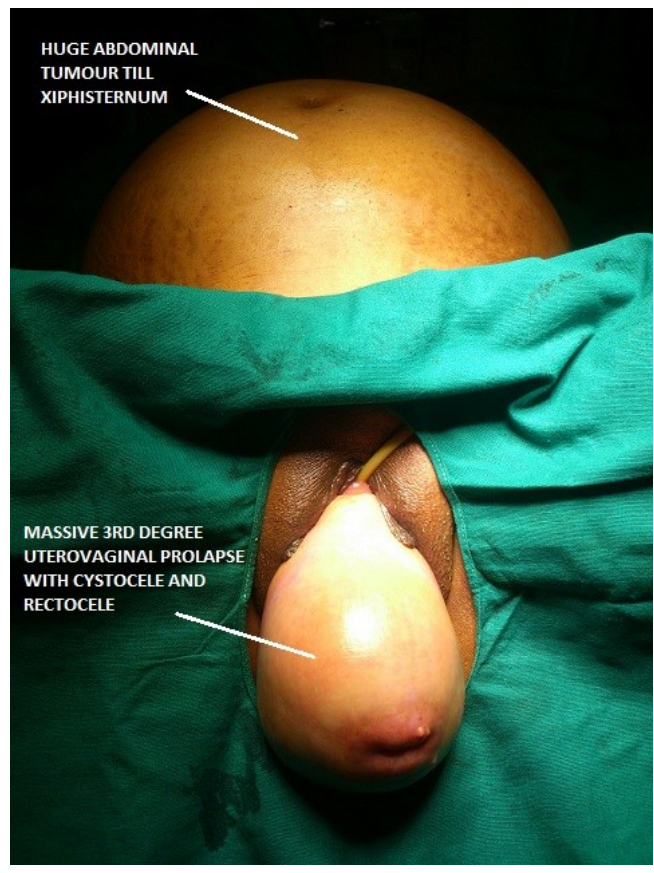

Figure 1: Showing clinical picture of huge abdominal mass with massive third degree uterovaginal prolapse with cystocele with rectocele.

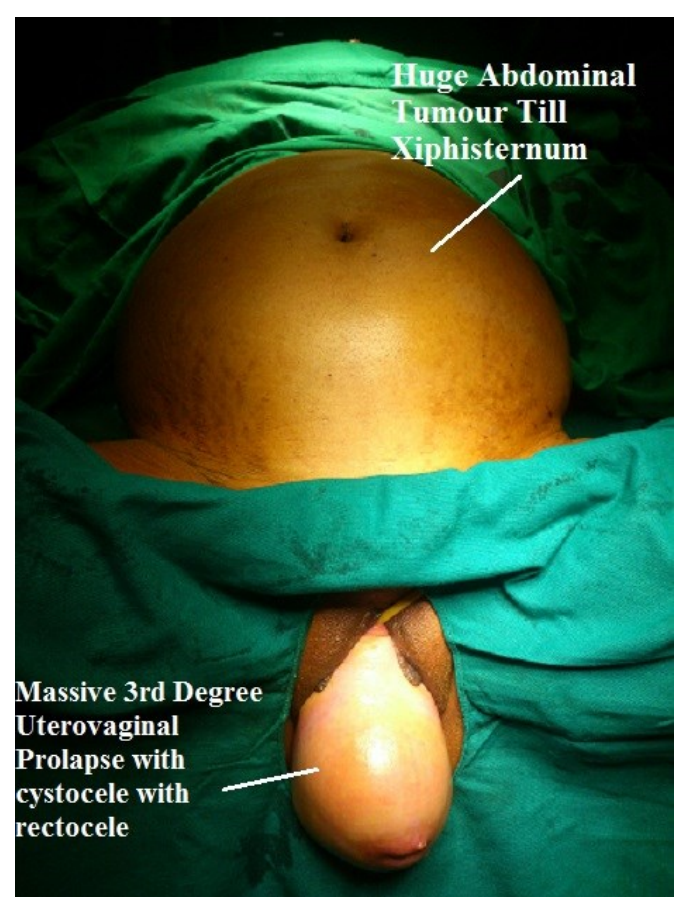

Figure 2: Showing clinical picture of huge abdominal mass with massive third degree uterovaginal prolapse with cystocele with rectocele. 


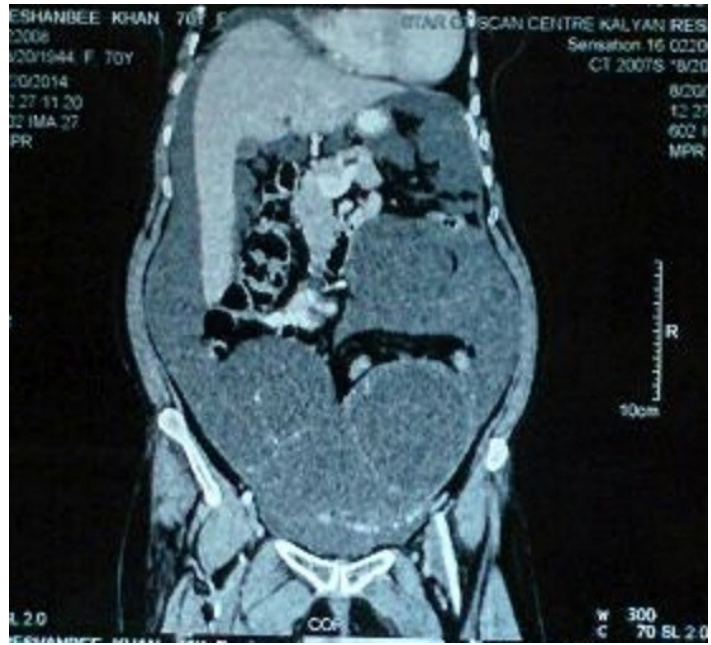

Figure 3: Showing computed tomography imaging of ovarian mass.

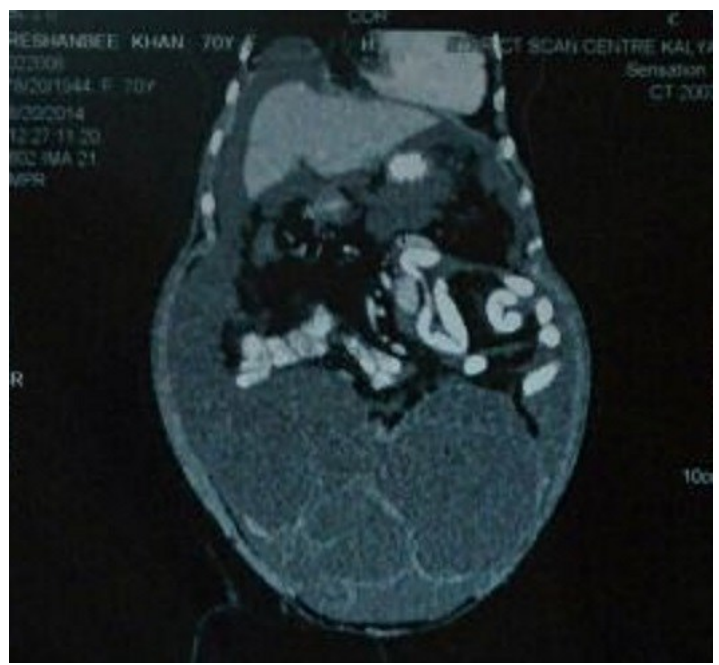

Figure 4: Showing computed tomography imaging of ovarian mass.

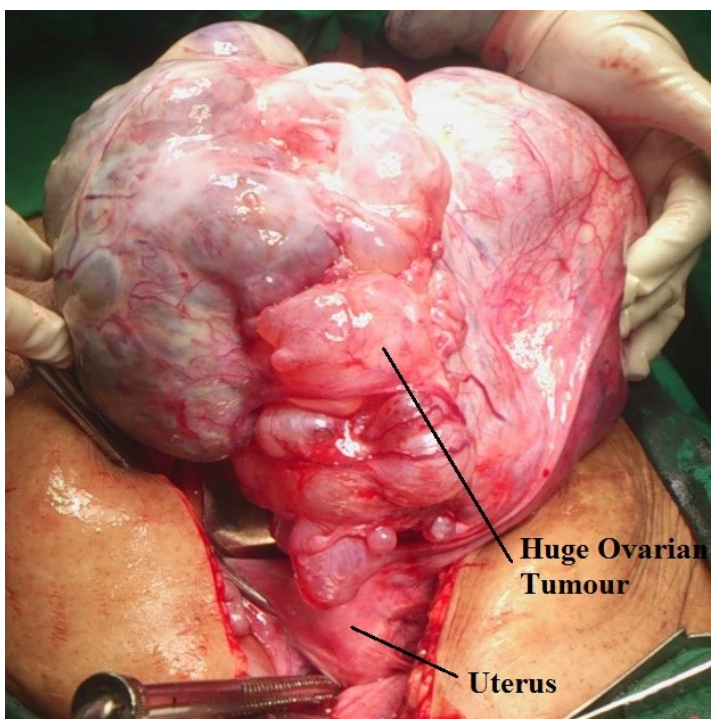

Figure 5: Showing huge ovarian mass.

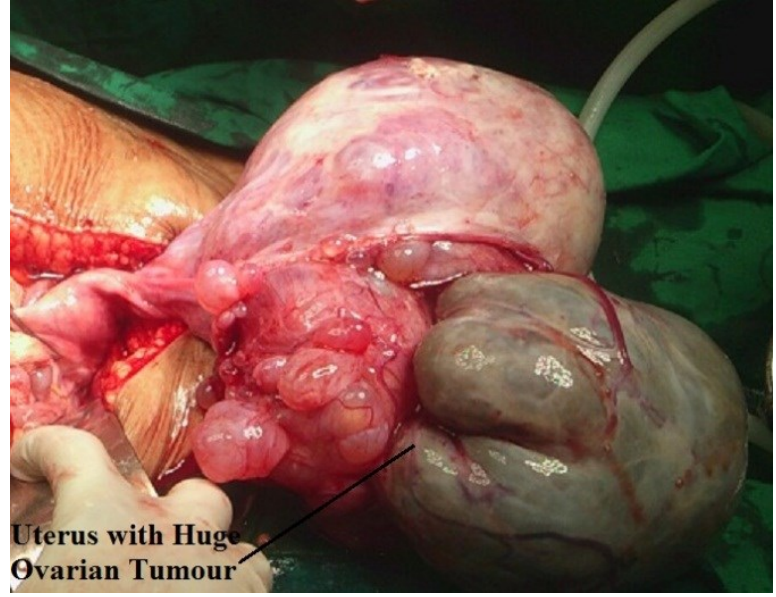

Figure 6: Showing huge ovarian mass.

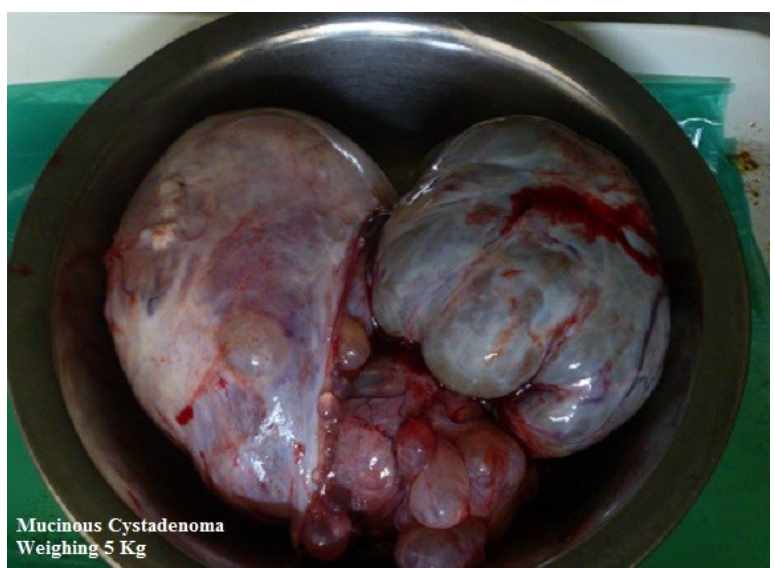

Figure 7: Showing ovarian mass weighing around 5 kg.

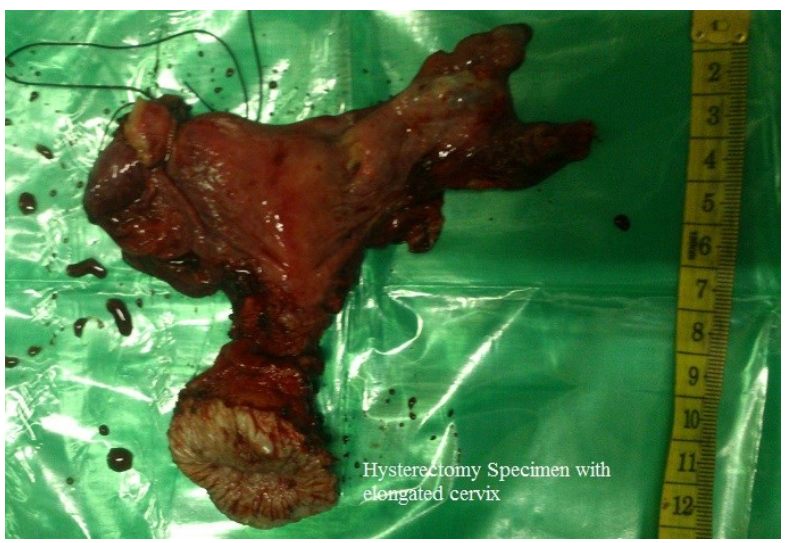

Figure 8: Showing hysterectomy specimen.

\section{DISCUSSION}

Uterine here are four major categories of ovarian tumors:

1) Epithelial tumors (65\%-75\%) - serous or mucinous cystadenoma/carcinoma, clear cell carcinoma, Brenner tumor; 2) germ cell tumors (15\%) - dysgerminoma, embryonal cell cancer, choriocarcinoma, teratoma; 3 ) 
Sex-chord-stromal tumors (5\%-10\%) - granulosa cell tumor, thecoma, fibroma; 4) Metastatic tumors (10\%) uterine, stomach, colon, breast, lymphoma. ${ }^{5}$ These tumors are usually evaluated using ultrasound, CT scan, or MRI. Findings on imaging studies are non-specific. These ovarian tumors may be multi-septated, cystic masses with thin walls. They may contain varying amounts of solid tissue which consists of proliferating stromal tissue, papillae, or malignant tumor cells. Tumour markers may also aid us in telling us the origin of the tumour. Mucinous cystadenomas are divided into three categories: benign, borderline, and malignant. Survival is largely dependent on the histology of the tumor, with 10 year survival rate of $100 \%$ for benign tumors, $60 \%$ for borderline tumors, and only $34 \%$ for the malignant subtype. Benign mucinous tumors tend to present earlier, while malignant tumors are often seen later in life. Benign mucinous cystadenomas comprise $80 \%$ of mucinous ovarian tumors and $20 \%-25 \%$ of benign ovarian tumors overall. The peak incidence occurs between 30-50 years of age. Benign tumors are bilateral in $5 \%-10 \%$ of cases. Borderline mucinous cystadenomas make up about $10 \%$ of mucinous ovarian neoplasm's and are bilateral in $10 \%$ of cases. Malignant mucinous cystadenoms are rare, and encompass $10 \%$ of mucinous ovarian tumors and $5 \%-10 \%$ of primary malignant ovarian neoplasms overall. They are bilateral in $15 \%$ $30 \%$ of cases and have a peak incidence between $40-70$ years of age. Giant ovarian tumours have become rare in current medical practice, as most cases are discovered early during routine check-ups. Detection of ovarian cysts causes considerable worry for women because of fear of malignancy, but fortunately the majority of ovarian cysts are benign. These giant tumours may be associated with pressure symptoms, urinary tract changes, respiratory embarrassment and debilitation. While operating on such tumours care has to be taken to manage these complications as well as the problems associated with sudden decompensation of such large tumours. Histologically, mucinous cystadenoma is lined by tall columnar non-ciliated epithelial cells with apical mucin and basal nuclei. $80 \%$ tumours are cystadenomas while the remaining $20 \%$ is of the borderline variety, noninvasive (intraglandular; intraepithelial) carcinomas, or invasive carcinomas. The borderline tumors may be of intestinal type or mullerian (endocervical-like) type. The intestinal type tumors are by far the most common. ${ }^{6}$ Mucinous cystadenoma is a benign ovarian tumor. It is reported to occur in middle-aged women. It is rare among adolescents $^{7}$ or in association with pregnancy. On gross appearance, mucinous tumors are characterised by cysts of variable sizes without surface invasion. Only $10 \%$ of primary mucinous cystadenoma is bilateral. ${ }^{7}$ In our case, the tumor was unilateral, affecting the left ovary. The cyst was filled with sticky gelatinous fluid rich in glycoprotein. Management of ovarian cysts depends on the patient's age, the size of the cyst and its histopathological nature. Conservative surgery as ovarian cystectomy and salpingo- oophorectomy is adequate for benign lesions. ${ }^{7}$

\section{CONCLUSION}

Here we have presented a huge mucinous cystadenoma with huge uterovaginal prolapse, with pressure symptoms. The cause of massive $3^{\text {rd }}$ degree uterovaginal prolapse with cystocele with rectocele in this case could be huge abdominal mass of 36 weeks of uterus size. Exploratory Laparotomy with excision of large ovarian tumour with frozen section followed by Total Abdominal Hysterectomy was done. Final histopathology report was mucinous cystadenoma of ovary. Patient was discharged in healthy condition.

\section{Funding: No funding sources \\ Conflict of interest: None declared \\ Ethical approval: Not required}

\section{REFERENCES}

1. Grubor NM, Colovic RB, Atkinson HD, Micev MT. Giant biliary mucinous cystadenoma of the liver. Ann Hepatol. 2013;12(6):979-83.

2. Hart WR. Mucinous tumors of the ovary: a review. Int J Gynaecol Pathol. 2005 Jan;24(1):4-25.

3. Katke RD. A huge benign mucinous cystadenoma of ovary: a case report and review of literature. Int J Reprod Contracept Obstet Gynaecol. 2014 Nov;3(2):456-9.

4. Katke RD, Kiran U. Giant borderline mucinous cystadenoma with previous 3 caesareans. J Postgraduate Gynaecol Obstet. 2014;1(9):1-4.

5. Scully RE. Classification of human ovarian tumors. Environ Health Persp. 1987;73:15-25.

6. Hart WR. Mucinous tumors of the ovary: a review. Int J Gynaecol Pathol. 2005;24:4-25.

7. Alobaid AS. Mucinous cystadenoma of the ovary in a 12-year-old girl. Saudi Med J. 2008;29:126-8.

DOI: $10.5455 / 2320-1770$. ijrcog20150249

Cite this article as: Katke RD. Huge mucinous cystadenoma of ovary with massive third degree uterovaginal prolapse in postmenopausal woman: rare case report and review of literature. Int $\mathrm{J}$ Reprod Contracept Obstet Gynecol 2015;4:255-8. 